\title{
Recent important strategies in the management of chronic kidney disease
}

\author{
A M Meyers, ${ }^{1}$ MB BCh, FCP (SA), FRCP (Lond), Cert Nephrology (SA) Phys; M Davies, ${ }^{2}$ MB BCh, FCP (SA), Cert Nephrology (SA) Phys \\ ${ }^{1}$ National Kidney Foundation of South Africa, Johannesburg; School of Clinical Medicine, Faculty of Health Sciences, University of the Witwatersrand, \\ Johannesburg; Faculty Practice Centre, Donald Gordon Medical Centre, Johannesburg; and Renal Dialysis Unit, Klerksdorp Hospital, South Africa \\ ${ }^{2}$ Division of Nephrology, Charlotte Maxeke Johannesburg Academic Hospital; and School of Clinical Medicine, Faculty of Health Sciences, University \\ of the Witwatersrand, Johannesburg, South Africa
}

Corresponding author: A M Meyers (nkfsa@mweb.co.za)

\begin{abstract}
The burden of chronic kidney disease (CKD) is considerably higher in low- and middle-income countries, which are less able than the developed world to cope with treating advanced renal failure owing to financial constraints. Prevention, early diagnosis and implementation of existing knowledge can improve outcomes. This review presents several recent advances to assist with avoiding and slowing down CKD progression and reducing common comorbid complications. The following are discussed: the possible use of metformin in patients with type 2 diabetes-related CKD; recent inexpensive important developments in the treatment of autosomal-dominant polycystic kidney disease; prevention of acidosis and the early dietary reduction of red meat consumption; and the therapeutic lowering of uric acid in persistent hyperuricaemia. Finally, an active and monitored exercise programme should be undertaken whenever possible. All of these recommendations have been shown to significantly slow the progression of CKD and increase cardiovascular protection.
\end{abstract}

S Afr Med J 2017;107(9):730-733. DOI:10.7196/SAMJ.2017.v107i9.12366

The global burden of non-communicable diseases (NCDs) is of grave concern and has recently been highlighted by the World Health Organization (WHO) and a plethora of publications in prominent journals. ${ }^{[1-3]}$ Chronic kidney disease (CKD) has often been indicated as a major contributing factor to this burden, especially in low- and middle-income countries. ${ }^{[4]}$ Initial figures stated that CKD was present in $10 \%$ of the world's population. Recently, this figure has risen to $14 \%$ in the USA, and by 2030, 27\% of North Americans $>30$ years of age are predicted to have $\mathrm{CKD}{ }^{[4]}$ An added burden to the recent number of people with CKD $>45$ years old will be markedly increased, taking into consideration that the estimated glomerular filtration rate (eGFR) decreases by $0.75-1.00 \mathrm{~mL} / \mathrm{min}$ and, for example, $50 \%$ of UK children born in 2007 will live to the age of 103 years. ${ }^{[5]}$ Although no figures for CKD are available in South Africa (SA), it is highly likely that these will be higher in the majority of the SA public, given that end-stage renal failure (ESRF) (CKD stage 5) is 3 - 4 times more prevalent in Afro-Americans. ${ }^{[6]}$ Mayosi et al. ${ }^{[7]}$ have shown that chronic renal failure (CRF) was the fifth most common cause of death in SA in 2006. The graph depicted in their article refers to deaths from nephritis/nephrosis only; therefore, the figure would probably have been much higher on the list if other causes of 'renal death', i.e. ESRF, were included. Permutations on how to prevent, diagnose, effectively treat and slow progression to ESRF, published in the CME section of the March and April 2015 editions of the SAMJ, were supported by a guest editorial written by the Minister of Health, Dr A Motsoaledi. ${ }^{[8-10]}$ This was followed by a ministerial summit held in Ekurhuleni in March 2015 on how to handle the burden of CKD in our resource-limited country. An additional burden is that the 2014 Renal Registry reported that $9.3 \%$ of all patients with ESRD on dialysis are HIV-positive. We believe that prevention, early detection and significantly slowing the progression of renal functional deterioration are of pivotal importance. The guidelines on how to achieve these skills are well illustrated in the SAMJ CME articles and in the Kidney Disease: Improving Global Outcomes (KDIGO) guidelines for $\mathrm{CKD}^{[11]}$ (the latter are currently being reviewed, specifically for low- and middle-income countries). We urge all relevant health personnel in the public, private and government sectors to read these guidelines.

To clarify the classification of CKD, a simplified version is shown in Table 1. As $<10 \%$ of the calculated potential sufferers of ESRF in the public sector of SA are able to receive renal replacement therapy (RRT), prevention strategies demand the utmost attention and are of essential importance in all healthcare protocols.

Since the publication of the guideline of the National Kidney Foundation of South Africa (NKFSA), various new avenues for prevention/slowing progression have come to light. The six 'caveats', which form the basis of this article, are shown in Table 2 and are discussed in that order.

\section{Diabetes and metformin}

Metformin (MF) must be regarded as the gold standard of treatment in patients with type 2 diabetes mellitus (DM) ${ }^{[12]}$ Its advantages are shown in Table 3. Of particular relevance is the continually increasing number of patients $<50$ years of age diagnosed with diabetes. In

Table 1. Clinical stages of chronic kidney disease

\begin{tabular}{lll}
\hline Stage & $\begin{array}{l}\text { Glomerular filtration } \\
\text { rate }(\mathbf{m L} / \mathbf{m i n})\end{array}$ & Comments \\
\hline CKD 1 & $90-110$ & Normal function \\
CKD 2 & $60-89$ & Asymptomatic \\
CKD 3a & $45-59$ & Subclinical symptoms \\
CKD 3b & $30-44$ & Mild clinical symptoms \\
CKD 4 & $15-29$ & $\begin{array}{l}\text { Moderate to severe } \\
\text { symptoms }\end{array}$ \\
CKD 5 & $<15$ & At or nearly at ESRF \\
CKD = chronic kidney disease; ESRF = end-stage renal failure.
\end{tabular}


Table 2. Recent advances in slowing the progression of chronic kidney disease

\begin{tabular}{|c|c|}
\hline Modality & Method and mode of functional stabilisation \\
\hline iabetes & CKD stages \\
\hline ADPKD & Slowing CKD with statin therapy \\
\hline Acidosis & $\begin{array}{l}\text { Early treatment of mild acidosis using } \\
\text { bicarbonate (oral) }\end{array}$ \\
\hline olites & \\
\hline Uric acid & $\begin{array}{l}\text { Allopurinol to slow down progression from } \\
\text { CKD stage } 3 \mathrm{~b} \text { onwards }\end{array}$ \\
\hline \multicolumn{2}{|c|}{$\begin{array}{l}\mathrm{CKD}=\text { chronic kidney disease; } \mathrm{MF}=\text { metformin; } \mathrm{ADPKD}=\text { autosomal-dominant } \\
\text { polycystic kidney disease; } \mathrm{TMAO}=\text { trimethylamine } \mathrm{N} \text {-oxide. }\end{array}$} \\
\hline \multicolumn{2}{|c|}{ Table 3. Advantages of metformin } \\
\hline \multicolumn{2}{|c|}{$\begin{array}{l}\text { - Excellent absorption and widespread distribution } \\
\text { - Increases intracellular glucose uptake, especially in muscular } \\
\text { tissue } \\
\text { - Decreases insulin resistance } \\
\text { - Decreases hepatic glycogenolysis } \\
\text { - Decreases appetite } \\
\text { decreases the intensity of diabetic macro- and microvascular } \\
\text { of diabetes } \\
\text { - Does not cause hypoglycaemia } \\
\text { - Improves quality of life } \\
\text { - Moderate lowering effect on low-density lipoprotein cholesterol } \\
\text { - Inexpensive }\end{array}$} \\
\hline
\end{tabular}

addition to the multiple cardiovascular and renal complications of DM, renal dysfunction in the elderly is further compounded by the slow but progressive fall in glomerular filtration rate (GFR) in persons $>45$ years of age (i.e. $\pm 1 \mathrm{~mL} / \mathrm{min} /$ year) and also because people live longer.

For many years the US Food and Drug Administration (FDA), the Regulatory Cooperation Council (RCC) in Canada and other regulatory bodies have indicated that the use of $\mathrm{MF}$ is contraindicated in patients with mild and moderate CKD (stages $3 \mathrm{a}$ and $3 \mathrm{~b}$ ) owing to the rarely reported but life-threatening complication of lactic acidosis (LA) (serum lactate levels $\geq 15 \mathrm{mmol} / \mathrm{L}$ ).

That LA does not occur in patients who receive MF, with an estimated GFR (eGFR) of $50-30 \mathrm{~mL} / \mathrm{min}$., has been indicated in studies conducted by Inzucchi et al. ${ }^{[13]}$ They showed that MF can be safely used in these patients, provided that certain guidelines are always followed. A Cochrane meta-analysis conducted on 47096 patients with a follow-up of 86067 patient-years compared the incidence of LA in patients who received MF with those who did not, irrespective of the eGFR. ${ }^{[14]}$ They found that for the upper limit of $95 \%$ confidence the true incidence of LA was 6.3/100 000 patient-years for the MF group and 7.8/100 000 patient-years for the non-MF group.

It is important to remember that before prescribing MF for any degree of renal function, certain rules are essential and must be fully adhered to. As many practitioners are either unaware or uncertain of the predisposing conditions, these are set out in Table 4

Mechanisms of MF-associated LA are not well elucidated, but include conversion of glucose to lactate in the splanchnic bed and inhibition of hepatic gluconeogenesis (i.e. from lactate, pyruvate and adenine). ${ }^{[15,16]}$
Table 4. Factors precipitating lactic acidosis in patients with type 2 diabetes mellitus

- Cardiac failure

- Myocardial infarction

- Hepatic failure

- Any hypoxic state

- Clinical dehydration

- Shock (especially septic shock)

- Severe sepsis and haemodynamic instability

- Major surgery

It is essential that any patient with the abovementioned precipitating disorders is instructed to immediately but temporarily withdraw the use of MF and present to a doctor. Patients have to be instructed in writing of the abovementioned dangers. If the warnings are adhered to, it is uncertain whether even CKD stage 4 or 5 per se could cause LA. However, it still remains preferable to avoid MF in the abovementioned patient cohorts until further information is available. Of note, to date only 4 patients with ESRF on peritoneal dialysis, who were on MF, have developed LA. Three of the 4 had LA-precipitating factors, as mentioned in Table $4 .{ }^{[17]}$

The dialysate in continuous ambulatory peritoneal dialysis (CAPD) contains lactate that may predispose to LA, even in the presence of normal hepatic function; it is a definite contraindication to the use of MF. A literature search on LA in haemodialysis (HD) yielded no data, probably because of non-usage of MF. However, HD utilises a bicarbonate buffer in the dialysate and, therefore, carefully conducted research into MF use may be of value.

The reason for emphasising the use of MF in CKD relates to both its immense value in glucose control in DM and to the necessity of slowing/preventing progression of both ESRF and cardiovascular disease (CVD) complications in a country with limited resources for the adequate funding of RRT. The last important consideration is that for many reasons patients with CKD stage 4 or 5 or those on dialysis commonly exhibit widely fluctuating glucose levels. Hypoglycaemia is extremely common, not only in patients receiving insulin but also because of drug accumulation in those on oral antidiabetic drugs.

Dipeptidyl peptidase-4 inhibitors (i.e. incretins) together with basal long-acting insulin would be the safest in the case of HD. ${ }^{[18]}$ The addition of MF would need to be carefully studied, if considered.

Also to be noted in the treatment of diabetes is the development of a novel, potentially life-saving, antidiabetic class of drug, the sodiumglucose cotransporter-2 (SGLT-2) inhibitors. ${ }^{[19]}$ These drugs block the proximal tubular reabsorption of glucose, leading to glycosuria. It also results in increased sodium loss. Other beneficial effects described were: $(i)$ excellent diabetic control; (ii) no side-effects and very well tolerated; (iii) marked reduction in hypertension and vascular morbidity; and (iv) significant renoprotection. If used early on in the disease, it could theoretically prevent most of the comorbid vascular and renal effects of sub-optimally treated type 2 diabetes. The first of this new class of drug has recently been registered in SA, i.e. empagliflozin.

\section{Autosomal-dominant polycystic kidney disease}

It has been reported that autosomal-dominant polycystic kidney disease (ADPKD) occurs in 1:1 000 people. ${ }^{[20]}$ The AD in ADPKD has been changed from adult to autosomal-dominant because the disease can manifest not only in childhood, but even in utero. ${ }^{[21,22]}$ In an excellent and recent review of genetics and pathogenetic mechanisms of cyst formation, clinical and diagnostic investigation parameters 
and recent treatments, Mochizuki et al. ${ }^{[20]}$ outlined several potential therapies for ADPKD. Tolvaptan and the vasopressin V2-receptor antagonists that inhibit cyst and kidney volume growth have been shown to be of value in the treatment of ADPKD. However, the effects are partial, there are many side-effects and the agents would probably be prohibitively expensive in SA. Likewise, somatostatin (octreotide) and the mammalian target of rapamycin (mTOR) inhibitor rapamycin have been used, but with limited or disappointing results, and are also excessively expensive. ${ }^{[20,23]}$

Cadnapaphornchai et al. ${ }^{[24]}$ recently reported on the prevention of a reduction in kidney volume and cyst growth, which was accompanied by kidney functional stability, using pravastatin in children and adults, with striking results. The use of statins is not new and both experimental and clinical mechanisms of renal protection in ADPKD have previously been shown. The mechanisms underlying the effects of statins on renal structural protection are still speculative, but may be related to their ability to prevent synthesis of certain isoprenoids that prevent post-translational modification of proteins such as Ras and Rho. Their signal translation would be altered, affecting cell proliferation and polarity. The blockage of these isoprenoids would reduce formation and growth of kidney cysts. In addition, statins inhibit angiogenesis. ${ }^{[24]}$ It would be interesting to investigate whether the production of glycogen synthase kinase- $3 \beta$ (GSK3 $\beta$ ) is altered. GSK3 $\beta$ has recently been shown to play a role in ADPKD via induction of proliferation of cystic epithelial cells.

The following recommendations have been suggested. All children from the age of $\sim 10$ years and all adults from ADPKD families should be screened using magnetic resonance imaging (MRI) or computed tomography (CT), but not renal ultrasound (due to the considerable number of negative results). High-dose statins must be administered, e.g. atorvastatin $40-80 \mathrm{mg}$ or rosuvastatin $20-40 \mathrm{mg}$ is probably preferable to pravastatin. Even at these doses, generics are inexpensive, but the usual side-effects should be monitored. It should be noted that statins have not been approved for use in ADPKD. The risks and benefits should be discussed with patients and relatives, and should include either signed parental or patient consent. In a disease that is responsible for $5-8 \%$ of all cases of ESRF, statins present a major and affordable preventive treatment in patients with ADPKD and constitute a significant advance in the management of these patients.

\section{Acidosis}

Recent studies have focused on the harm that small changes in the level of blood acidity can cause, even in patients with mild renal dysfunction (CKD stage 2). Łoniewski and Wesson ${ }^{[25]}$ discuss various possible causes of renal damage caused by chronic acidosis, such as increased endothelin, aldosterone and angiotensin II production, inflammation and renal fibrosis.

In support of the necessity to control acidosis, there are two further studies. Banerjee et al. ${ }^{[26]}$ have clearly shown that dietinduced acid load is associated with increased risk of ESRF. They demonstrated that worsening of metabolic acidosis was highly significantly associated with a decrease in GFR and concluded that acidosis in CKD is independently associated with an increased risk of ESRF. $^{[26]}$ Secondly, a recent study from the University of Manchester, UK, showed that small changes in blood acidity are associated with an increase in parathyroid secretion, resulting in removal of calcium and phosphate from bones with arterial metastatic deposition. ${ }^{[27]}$ The optimal $\mathrm{NaHCO}_{3}$ dose remains to be determined, but the current recommendations state a dose of $0.5-1.0 \mathrm{mmol}$ of $\mathrm{NaHCO}_{3} / \mathrm{kg}$ body weight in three divided doses per day, i.e. 1 or 2 small salt spoons of baking soda three times a day with meals.
Many pathogenetic mechanisms in the progression of renal dysfunction associated with metabolic acidosis have been demonstrated, which mandates active and ongoing prevention of acidosis in patients with moderate to mild CKD. Of note is the recommendation that only sodium bicarbonate should be used, as agents such as sodium citrate could pose a threat of increased dietary aluminium absorption in patients with more advanced CKD, but who are not yet on dialysis. ${ }^{[28,29]}$

\section{Gut bacterial by-products linked to CKD progression and CKD-associated cardiovascular disease}

Recent studies have suggested involvement of gut bacteria in the generation of metabolites that display uraemic toxicity. Further experiments by Tang et al. ${ }^{[30]}$ investigated the effects of gut microbial-dependent trimethylamine $\mathrm{N}$-oxide (TMAO) in patients with CKD. Elevated TMAO plasma levels were demonstrated in patients with CKD and have been shown to contribute significantly to progressive renal fibrosis, CVD and poorer long-term survival. Studies in animals that were fed an increased content of TMAO in their diet confirmed a marked increase in renal fibrosis and dysfunction. Furthermore, in a cohort of people with normal renal function but on a high meat diet, the risk of microalbuminuria has been clearly demonstrated. ${ }^{[1,32]}$ TMAO metabolites comprise choline, phosphatidylcholine (lecithin) and L-carnitine, and the levels are particularly high in red meat, liver, other meats and egg yolk. Lower levels are found in poultry. It is important to remember that choline is an essential nutrient that can be obtained from red meat, as well as from fish, poultry and eggs. Therefore, in recommending avoidance of or a stringent reduction in the ingestion of red meat and pork, one could reasonably anticipate that this will significantly slow renal functional decline even before the results of interventional studies are available. Two further strong theoretical points support the supposition that avoidance of red meat significantly reduces the hydrogen ion dietary load (discussed above). Red meats contain significantly more phosphate than poultry and fish. It is known that, because a decrease in renal phosphate clearance occurs early on in CKD, even a mild tendency to increase the body's phosphate levels increases the production of fibroblast growth factor 23 (FGF23) and depresses the Klotho FGF23-receptor pathway. ${ }^{[33,34]}$ This effect will result in a decrease in the activity of the renal tubular 1a-reductase enzyme, resulting in a significant reduction in the conversion of inactive vitamin $\mathrm{D}_{3}$ into active vitamin $\mathrm{D}_{3}$ (calcitriol). Therefore, less calcium will be absorbed in the gut, eventually resulting in hypocalcaemia and secondary hypoparathyroidism, which is a well-known factor in the genesis of progressive renal functional deterioration.

Because of severe financial constraints in the treatment of advanced CKD in SA, it seems prudent to suggest this dietary advice in anyone with an eGFR of $\leq 50 \mathrm{~mL} / \mathrm{min}$.

\section{Serum uric acid}

Observational studies suggest that uric acid (UA) is an independent predictor of both progression of CKD and increased mortality from CVD. It has also been proposed that an elevated UA may have a role in initiating hypertension, nephrosclerosis and insulin resistance. ${ }^{[35-38]}$ These are not new findings, but it is currently uncertain whether a raised UA acts as a nephrotoxin, vasculotoxin, or marker of a high acid-ash (protein) diet or reduced eGFR. Although trials have demonstrated slowing of CKD progression in patients treated with allopurinol, the numbers are limited. Both the KDIGO, USA, and 
the National Institute for Clinical Excellence (NICE), UK, do not recommend UA-lowering therapy. However, there is a plethora of experimental studies that support the notion that UA reduction may not only be renoprotective but may be important in reducing CVD mortality. ${ }^{[39]}$ As CVD is a major risk factor in CKD, and as RRT is so limited, it would not seem unreasonable to recommend careful use of allopurinol in patients with asymptomatic hyperuricaemia from CKD stage 3 onwards, commencing when the UA level rises above the normal range. All dietary measures should be tried before administering allopurinol. In a key article, Kang and Nakagawa ${ }^{[38]}$ stated that experimental data using hyperuricaemic animals and cultured cells provide robust evidence regarding hypertension, proteinuria, vascular disease and progressive renal scaring. Nevertheless, in 1984 Hande et al. ${ }^{[40]}$ reported on severe allopurinol toxicity with fever, rash, eosinophilia and worsening of renal function in 78 patients with varying degrees of CKD. However, all 78 patients received concomitant thiazide diuretics for hypertension. Since that publication, rare cases of this syndrome have been reported in patients with CKD and normal renal function. It is considered as an idiosyncratic reaction that occurs very rarely.

Our advice is to start allopurinol in small doses (e.g. $100 \mathrm{mg} /$ day), monitor the patient and titrate up to produce an adequate UA-lowering effect if no toxicity is found. Furthermore, we would recommend that if a CKD patient is receiving a thiazide, allopurinol should be avoided.

\section{Exercise}

There are many studies investigating the effects of exercise in patients with CKD who are not on dialysis. The results are encouraging and have demonstrated multiple benefits in both slowing progression and reducing mortality (Table 5). ${ }^{[41]}$

All exercise training programmes should be evaluated and supervised by trained medical personnel and the patient's clinical status carefully evaluated before prescribing exercise.

Table 5. Exercise and chronic kidney disease

\begin{tabular}{ll}
\hline Type of exercise & Benefit \\
\hline Resistance training & Decrease in CRP and IL-6 \\
Swimming & Decrease in oxidative stress and \\
& $\mathrm{BP}$, and increase in eGFR \\
& Improved $\mathrm{VO}_{2}$ max, BP and eGFR \\
General exercise & $\mathrm{CRP}_{2}=\mathrm{C}$-reactive protein; IL-6 = interleukin 6; $\mathrm{VO}_{2} \max =$ maximum volume of oxygen; \\
$\mathrm{BP}=$ blood pressure; eGFR = estimated glomerular filtration rate.
\end{tabular}

\section{Conclusion}

As financial constraints in SA permit that only a fraction of public sector ESRF patients are able to receive RRT, it would be logical to use all safe mechanisms to slow progressive loss of GFR. Therefore, apart from the usual advice of smoking cessation, alcohol moderation, maintaining ideal body weight, avoiding nephrotoxins, maintaining blood pressure and blood sugar at target levels, and reducing proteinuria using well-known prescribed methods, we advise the use of all other possible but safe modalities to slow functional deterioration. The safe use of MF in CKD (excluding CKD stage 5), early screening and safe inexpensive treatment of patients with ADPKD, use of allopurinol in the absence of gout to decrease UA levels, treatment of acidosis and dietary and prescribed exercise programmes should be included in the list of progression-slowing procedures. Of note is that even this extended list indicates that changes in lifestyle as well as therapeutic measures should be employed.
1. Tha V, Garcia-Garcia G, Iseki K, et al. Chronic kidney disease: Global dimension and perspectives. Lancet 2013;382(9888):260-272. https.//doi.org/10.1016/S0140-6736(13)60687-X

2. Couser WG, Remuzzi G, Mendis S, Tonelli M. The contribution of chronic kidney disease to the global burden Couser WG, Remuzzi G, Mendis S, Tonelli M. The contribution of chronic kidney disease to the global burden
of major noncommunicable diseases. Kidney Int 2011;80(12):1258-1270. https://doi.org $/ 10.1038 /$ ki.2011.368 of major 3. World Health Organization. Preventing Chronic Diseases: A Vital Investment. Geneva: WHO, 2005. 4. Hoerger TJ, Simpson SA, Yarnoff BO, et al. The future burden of CKD in the United States: A simulation model for the CDC CKD Initiative. Am J Kidney Dis 2015;65(3):403-411. https://doi.org/10.1053/j.ajkd.2014.09.023 5. Select Committee on Public Service and Demographic Change, House of Lords, London, UK. Ready for ageing? 2013. http://www.publications.parliament.uk/pa/ld201213/ldselect/ldpublic/140/14003. htm (accessed 4 April 2017)

6. World Kidney Day. Kidney health for all. 2015. www.worldkidneyday.org/resource/kidney-healthpress-release-2015/ (accessed 4 April 2017)

7. Mayosi BM, Flisher AJ, Lalloo UG, Sitas F, Tollman SM, Bradshaw D. The burden of non-communicable diseases in South Africa. Lancet 2009;374(9693):934-947. https://doi.org/10.1016/S0140-6736(09)61087-4 Motsoaledi A Chronic kidney disease. S Afr Med J 2015:105(4). https//doi org/10.7196/samp.9620

9. Meyers AM, Assounga AG, Gerntholtz T, et al. Chronic kidney disease. S Afr Med J 2015;105(3):232-237. Meyers AM, Assounga AG, Gerntholtz T, et al. Chronic ki
https://doi.org/10.7196/samj. $9444 / 9412 / 9414 / 9417 / 9413$

10. Meyers AM, Mahala B, Moosa MR, et al. Chronic kidney disease. S Afr Med J 2015;105(4):316-322. . Meyers AM, Mahala B, Moosa MR, et al. Chronic
https://doi.org/10.7196/samj.9532/9535/9536/9537

11. Kidney Disease: Improving Global Outcomes (KDIGO) CKD Work Group. KDIGO 2012 clinical practice guideline for the evaluation and management of chronic kidney disease. Kidney Int 2013;(Suppl 3):1-150. https://doi.org/10.1038/kisup.2012.76

12. Bailey CJ, Campbell IW, Chan JCN, Davidson JA, Howlett HCS, Ritz P. Metformin, the Gold Standard - A Scientific Handbook. Chichester, UK: John Wiley, 2007.

13. Inzucchi SE, Lipska KJ, Mayo H, Bailey CJ, McGuire DK. Metformin in patients with type 2 diabetes and kidney disease: A systematic review. JAMA 2014;312(24):2668-2675. https://doi.org/10.1001/jama.2014.15298

14. Salpeter S, Greyber E, Pasternak G, Salpeter E. Risk of fatal and nonfatal lactic acidosis with metformin use in type 2 diabetes mellitus. Cochrane Database Systematic Review 2006;25(1):CD002967. https:// doi.org/10.1002/14651858.CD002967.pub2

15. Bailey CJ, Wilcock C, Day C. Effect of metformin on glucose metabolism in the splanchnic bed. Br J Bailey CJ, Wilcock C, Day C. Effect of metformin on glucose metabolism in the splanc
Pharmacol 1992;105(4):1009-1013. https://doi.org/10.1111/j.1476-5381.1992.tb09093.x

16. Sirtori CR, Pasik C. Re-evaluation of a biguanide, metformin: Mechanism of action and tolerability. Pharmacol Res 1994;30(3):187-228. https://doi.org/10.1016/1043-6618(94)80104-5

17. Almaleki N, Ashraf M, Hussein MM, Mohiuddin SA. Metformin-associated lactic acidosis in a peritoneal dialysis patient. Saudi J Kidney Dis Transpl 2015;26(2):325-328. https://doi.org/10.4103/1319-2442.152498

18. Perkovic V, Agarwal R, Fioretto P, et al. Management of patients with diabetes and CKD: Conclusions from a Kidney Disease: Improving Global Outcomes (KDIGO) Controversies Conference. Kidney Int 2016;90(6):1175-1183. https://doi.org/10.1016/j.kint.2016.09.010

19. Heerspink HJL, Desai M, Jardine M, Balis D, Meininger G, Perkovic V. Canagliflozin slows progression of renal function decline independently of glycemic effects. J Am Soc Nephrol 2017;28(1):368-375, https://doi.org/10.1681/ASN.2016030278

20. Mochizuki T, Tsuchiya K, Nitta K. Autosomal dominant polycystic kidney disease: Recent advances in pathogenesis and potential therapies. Clin Exp Nephrol 2013;17(3):317-326. https://doi.org/10.1007/ s10157-012-0741-0

21. Somlo S, Chapman AB. Autosomal dominant polycystic kidney disease. In: Schrier RW, Coffman TM, Falk RJ, Molitoris BA, Neilson EG. Schrier's Diseases of the Kidney. 9th ed. Philadelphia, USA: Lippincott Williams \& Wilkens, 2012:519-563.

22. MacDermot KD, Saggar-Malik AK, Economides DL, Jeffery S. Prenatal diagnosis of autosomal dominant polycystic kidney disease (PKD 1) presenting in utero and prognosis for very early onset disease. J Med Genet 1998;35(1):13-16.

23. Torres VE, Chapman AB, Devuyst O, et al. Tolvaptan in patients with autosomal dominant polycystic kidney disease. N Engl J Med 2012;367(25):2407-2418. https://doi.org/10.1056/NEJMoa1205511

24. Cadnapaphornchai MA, George DM, McFann K, et al. Effect of pravastatin on total kidney volume, left ventricular mass index, and microalbuminuria in pediatric autosomal dominant polycystic kidney disease. Clin J Am Soc Nephrol 2014;9(5):889-896. https://doi.org/10.2215/CJN.08350813

25. Łoniewski I, Wesson DE. Bicarbonate therapy for prevention of chronic kidney disease progression. Kidney Int 2014; 85(3):529-535. https://doi.org/10.1038/ki.2013.401
.

26. Banerjee T, Crews DC, Wesson DE, et al. High dietary acid load predicts ESRD among adults with CKD. J Am Soc Nephrol 2015;26(7):1693-1700. https://doi.org/10.1681/ASN.2014040332
CKDerjee T, Crews DC, Wesson DE, et al. High dietary acid load predicts ESRD among 27. Campion KL, McCormick WD, Warwicker J, et al. Pathophysiologic changes in extracellular ph
modulate parathyroid calcium-sensing receptor activity and secretion via a histidine-independent mechanism. J Am Soc Nephrol 2015;26(9):2163-2171. https://doi.org/10.1681/ASN.2014070653

28. Nestel AW, Meyers AM, Paiker J, Rollin HB. Effect of calcium supplement preparation containing small amounts of citrate on the absorption of aluminium in normal subjects and in renal failure patients. Nephron 1994;8(2):197-201.

29. Meyers AM. Regarding mini-review on bicarbonate therapy for prevention of chronic kidney disease progression. Kidney Int 2015;87(6):1260-1261. https://doi.org/10.1038/ki.2015.81

30. Tang WH, Wang Z, Kennedy DJ, et al. Gut microbiota-dependent trimethylamine N-oxide (TMAO) pathway contributes to both development of renal insufficiency and mortality risk in chronic kidney disease. Circ Res 2015;116(3):448-455. https://doi.org/10.1161/CIRCRESAHA.116.305360

31. Mafra D, Lobo JC, Barros AF, Koppe L, Vaziri ND, Fouque D. Role of altered intestinal microbiota in systemic inflammation and cardiovascular disease in chronic kidney disease. Future Microbiol in systemic inflammation and cardiovascular disease

32. Vaziri ND, Wong J, Pahl M, et al. Chronic kidney disease alters intestinal microbial flora. Kidney Int 2013;83(2):308-315. https://doi.org/10.1038/ki.2012.345

33. Saito T, Fukumoto S. Fibroblast growth factor 23 (FGF23) and disorders of phosphate metabolism. Int J Pediatr Endocrinol 2009;496-514. https://doi.org/10.1155/2009/496514

34. Wahl P, Wolf M. FGF23 in chronic kidney disease. Adv Exp Med Biol 2012;728:107-125. https://doi. org/10.1007/978-1-4614-0887-1_8

5. Zoccali C, Mallamaci F. Uric acid, hypertension, and cardiovascular and renal complications. Curr Hypertens Rep 2013;15(6):531-537. https://doi.org/10.1007/s1 1906-013-0391-y

36. Siu YP, Leung KT, Tong MK, Kwan TH. Use of allopurinol in slowing the progression of renal disease through its ability to lower serum uric acid level. Am J Kidney Dis 2006;47(1):51-59. https://doi. org/10.1053/j.ajkd.2005.10.006

37. Goicoechea M, de Vinuesa SG, Verdalles U, et al. Effect of allopurinol in chronic kidney disease progression and cardiovascular risk. Clin J Am Soc Nephrol 2010;5(8):388-393. https://doi.org/10.2215/CJN.01580210

38. Kang DH, Nakagawa T. Uric acid and chronic renal disease: Possible implication of hyperuricemia on progression of renal disease. Semin Nephrol 2005;25(1):43-49. https://doi.org/10.1016/j.semne-
of on progression of

39. Rekhraj S, Gandy SJ, Szwejkowski BR, et al. High-dose allopurinol reduces left ventricular mass in patients with ischemic heart disease. J Am Coll Cardiol 2013;61(9):926-932. https://doi.org/10.1016/j. jacc.2012.09.066

40. Hande KR, Noone RM, Stone WJ. Severe allopurinol toxicity - description and guidelines for prevention in patients with renal insufficiency. Am J Med 1984;76(1):47-56. https://doi.org/10.1016/0002-9343(84)90743-5

41. Morishita Y, Nagata D. Strategies to improve physical activity by exercise training in patients with chronic kidney disease. Int J Nephrol Renovasc Dis 2015;8:19-24. https://doi.org/10.2147/IJNRD.S65702 